\title{
Notas sobre otras epidemias en el Chile colonial
}

\author{
Enrique Laval
}

\section{Notes about other epidemics in Colonial Chile}

In chronicles or in the historiography of the Colony in Chile there are few references about epidemics different to smallpox; like typhus, typhoid fever, dysentery, etc. Almost all, fast spreading in the country and some with high lethality, which led to overflowing the capacity of hospitals in the chilean colonial period.

Key words: Malsito, breakbone, flank pain, congo, ball of fire.

Palabras claves: Malsito, quebrantahuesos, dolor de costado y romadizo, congo, la bola de fuego.

\section{Introducción}

$\mathrm{V}$ arias comunicaciones dan a conocer la carencia de higiene pública en la Colonia e informes oficiales se refieren al gran déficit de agua potable. Las fuentes o acequias desde donde se obtenía el agua para beber o cocinar, generalmente estaban llenas de barro e inmundicias.

Una Sociedad con tal realidad material estaba expuesta a toda clase de enfermedades infecciosas y por consiguiente, vulnerable a sus impactos. De hecho no existían medios útiles para combatir las epidemias: La viruela fue muy importante en 1765, "falleciendo la tercera parte de los atacados por ella".

En crónicas o en la historiografía del pasado, se encuentran pocas referencias a otras epidemias y plagas del Chile colonial ${ }^{1}$.

\section{Malsito o malesito}

Así se llamó a una enfermedad epidémica que atacó primordialmente a ciudades de Santiago y Concepción, que al ser los centros más poblados, sufrieron con mayor rigor de este contagioso mal. No está bien caracterizada esta epidemia: algunos la atribuyeron a un contagio traído por la escuadra española del Almirante Vacaro a Talcahuano, otros a "una descomposición atmosférica por un gran aluvión seguido de sequía", en tanto otros le dieron una fisonomía gripal: hubo quienes pensaron en fiebre amarilla, importada del Perú, y varios en "epidemic typhus" (tifus exantemático).

En Santiago, ante la imposibilidad de atender a todos los enfermos se habilitaron dos hospitales provisorios, uno de hombres en el Noviciado de los Jesuitas y otro de mujeres en la Casa de Huérfanos, en que se atendieron 3.978 enfermas desde octubre de 1779 , hasta enero de
1780 según lo manifestó el director de dicho Servicio, el regidor don José Miguel Prado, desconociéndose la letalidad. Hubo que dividir la ciudad en cuatro cuarteles sanitarios a cargo de diputados que vigilaban la asistencia pública.

Se distinguió en esta humanitaria campaña don Diego Portales, abuelo del histórico ministro, que durante la epidemia no dejó un solo día de asistir a los pacientes y auxiliarlos, siguiendo después su obra como mayordomo del hospital de mujeres y de la construcción del Hospital San Francisco de Borja, cargo que desempeñó caritativamente, sin interés pecuniario.

De 1.232 hombres que se internaron a partir del 2 de octubre de 1779 en el Hospital San Francisco de Borja, fallecieron 285 , hasta el 12 de marzo de $1780^{2,3}$.
Pontificia Universidad Católica de Chile.

Facultad de Medicina, Programa de Estudios Humanísticos.

Recibido: 19 de junio de 2015

Correspondencia a:

Enrique Laval R.

revinf@sochinf.cl

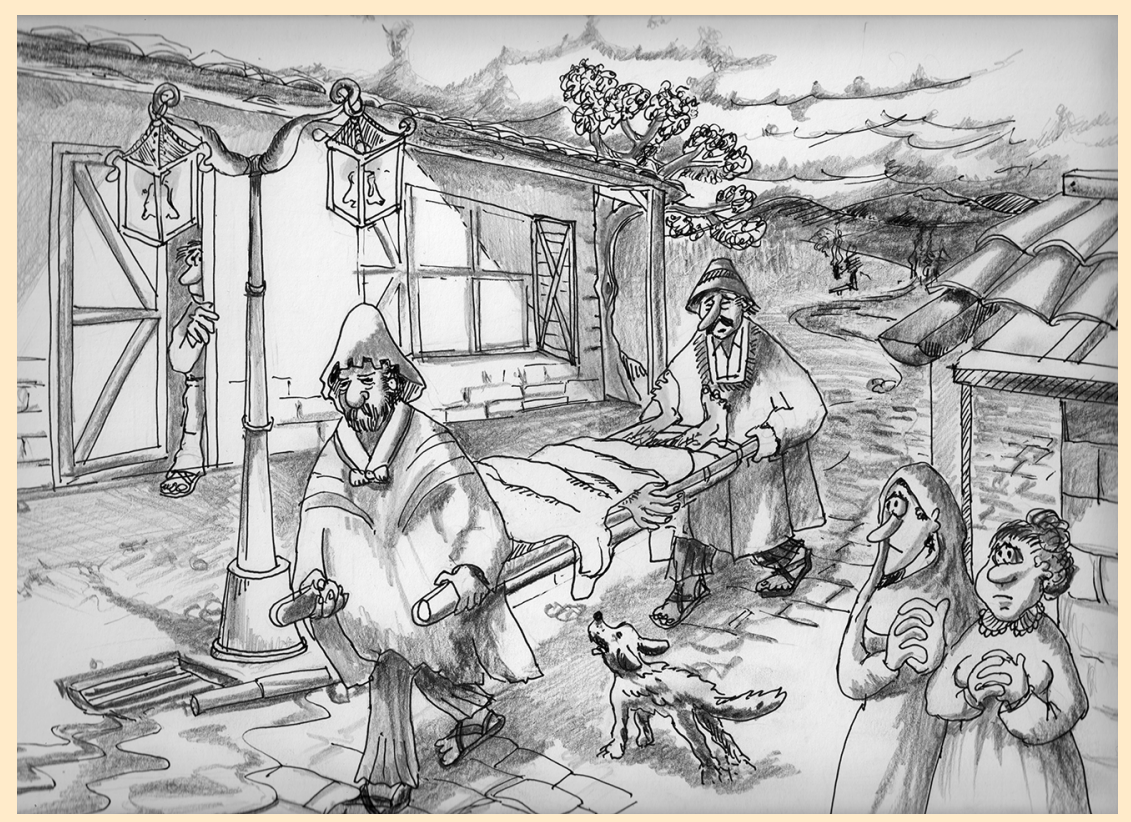


Históricamente, la epidemia mencionada de 17791780, fue muy importante. Algunas referencias aparecen en crónicas como Pérez García y Carvallo Goyeneche, de los cuales, historiadores nacionales del siglo XIX, como don Benjamín Vicuña Mackenna, don Diego Barros Arana y posteriormente don Francisco Antonio Encina, recogieron algunas características generales de ella. Fuera de señalar que se trataba de una "fiebre pútrida que mataba en tres días", los testimonios originales no especificaban los rasgos patológicos de la enfermedad. (ci. por 1).

Otros tipos de fuentes (como registros parroquiales, no siempre completos) nos señalaban que en Santiago y otros lugares del Valle Central, la epidemia ya había producido efectos mortales en 1779. Vicuña Mackenna la definió como fiebre amarilla. No obstante, si consideramos que el ambiente más propicio para tal enfermedad es el de los climas cálidos ausentes del Chile Central, tal afirmación no es fácil de aceptar. Como antecedente, sólo podría afirmarse que "la diarrea continuaba a la constipación inicial".

Por otra parte, en la misma época en Europa -aunque no enteramente aceptado- persistía la idea de que enfermedades como ésta se explicaban "por la existencia de aguas contaminadas subterráneas que desplazaban gases saturados de infección desde el suelo hacia la atmósfera".

Nos dice el historiador de la medicina chilena, doctor Eduardo Salas Olano, que en el año 1779, a la fiebre tifoidea se juntó otra enfermedad, el malesito, que por su rapidez en desarrollarse se creyó que sería tifus exantemático, cuyo origen correspondería "a la crecida y desborde del Río Mapocho", en mayo de aquel año.

\section{Quebrantahuesos}

Agrega Salas Olano, que la gripe o influenza hizo también su entrada al país, en 1658, pero de ella ha quedado el nombre con que la bautizara el vulgo: "quebrantahuesos". El siglo XVIII vio nuevamente amenazada la Colonia por dicha enfermedad, pero el Cabildo de Santiago avisado a tiempo, pudo tomar las medidas preventivas, ignorándose si ellas pudieron evitar la introducción de aquella. Supo el Cabildo en 1779, por una comunicación del virrey del Perú a don Agustín de Jáuregui, Gobernador de Chile, que en dicho año afligía a Lima una epidemia catarral, que no era otra que la gripe, reuniéndose en sesión extraordinaria, pidiendo al Gobernador algunas medidas de buena higiene. Parece necesario, que se sirva V. E. mandar por bando público, que todos los vecinos limpien sus acequias y boten fuera de la cuidad las inmundicias. A estas medidas y consejos del Cabildo, agregó el Gobernador, que los buques procedentes del Callao se sujetasen a la inspección de las autoridades de los puertos a donde llegasen e hiciesen cuarentena en Viña del Mar si arribaban a Valparaíso ${ }^{4}$.

Parecería procedente señalar lo escrito por don Benjamín Vicuña Mackenna sobre el absoluto desaseo de la ciudad de Santiago, casi 20 años después, existiendo una propuesta en 1798, hecha por un individuo de apellido Gálvez, en que se comprometía barrer las calles "una vez al mes" esto es, doce ocasiones en el año, lo que prueba que no fueron barridas jamás ${ }^{5}$.

\section{Epidemia de dolor de costado y romadizo}

Así se llamó una epidemia que se desarrolló en 1652 , según lo relatado por el capitán Lazo de la Vega, en carta a Felipe IV, que le ocasionó la pérdida de la mayoría de sus soldados. Laval Manrique piensa que a juzgar por la gran extensión del país que invadió rápidamente, pudo tratarse de gripe, coincidiendo con lo señalado por Pedro Lautaro Ferrer ${ }^{2,6}$.

\section{Congo}

Según Laval Manrique, apareció en Concepción, en 1782, una epidemia denominada "congo", que obligó a internar a los enfermos en la Casa de Ejercicios del Clero, siendo su naturaleza desconocida. Con este motivo el Cabildo, el 14 de junio, acordó solicitar del Gobernador una cuadra del terreno que pertenecía al Convento de San Francisco de dicha ciudad, para construir allí un hospital.

Algunos autores han creído que tal epidemia fue de viruela benigna, pero no habría antecedentes para aceptar o rechazar dicha opinión ${ }^{6}$.

\section{Epidemia de la bola de fuego}

Don Benjamín Vicuña Mackenna relata, que después de una gran epidemia de viruela, coetánea con el terremoto de julio de 1730, sobrevino, la epidemia que el vulgo llamó "de la bola de fuego" por haber coincidido con la caída de un aerolito en una isla desierta del archipiélago austral. Esto aconteció en tiempo del Gobernador Manso de Velasco, no existiendo datos suficientes para calificar su carácter mórbido 5 . Ferrer la menciona como probable gripe, dando ocasión a "mil supercherías entre los curanderos y hechiceros"

\section{Resumen}

En crónicas o en la historiografía de la Colonia en Chile existen pocas referencias acerca de otras epidemias distintas de la viruela, como el tifus exantemático, fiebre tifoidea, disentería, etc. Casi todas de difusión rápida 
en el país y algunas con letalidad alta, que condujeron a rebalsar la capacidad de los hospitales de la época colonial chilena.

\section{Referencias bibliográficas}

1.- Cavieres F E. Epidemias, Medicina y Sociedad Colonial. La plaga de 1779-80, en Chile. Cuadernos de Historia $\mathrm{N}^{\circ}$ 10 Depto. de Ciencias Históricas. Universidad de Chile. Diciembre de 1990.
2.- Ferrer P L. Historia General de la Medicina en Chile. Impta. Talca. Chile. 1904.

3.- Medina J T. Cosas de la Colonia. Fondo Histórico bibliográfico. Santiago de Chile. 1952.

4.- Salas Olano E. Historia de la Medicina en Chile. Impta. Vicuña Mackenna. Santiago de Chile, 1894.

5.- Vicuña Mackenna, B. Los Médicos de antaño en el Reino de Chile. Impta. De la Librería del Mercurio. Santiago de Chile, 1877.

6.- Laval M E. Desarrollo de la viruela en Chile. Desde la Conquista hasta 1825. Grajales. An Chil Hist Med 1967-68; 9-10: 203-276. 